\title{
Implementation and Evaluation of Mobile Shopping Services Based on RFID Sensing Technology
}

\author{
Tsai-Pei Liu, ${ }^{1}$ Yue-Yang Chen, ${ }^{2 *}$ and Jia-Ying $\mathrm{Yu}^{1}$ \\ ${ }^{1}$ Department of Distribution Management, National Taichung University of Science and Technology, \\ No. 129, Sec. 3, Sanmin Rd, North District, Taichung City 40401, Taiwan, R.O.C. \\ ${ }^{2}$ Department of Business Administration, I-Shou University, \\ No. 1, Sec. 1, Syuecheng Rd., Dashu District, Kaohsiung City 84001, Taiwan, R.O.C.
}

(Received November 19, 2020; accepted January 20, 2021)

Keywords: mobile shopping services, RFID sensing technology, C-TAM-TPB

We have developed a new shopping model that integrates modern sensing technologies. A combined technology acceptance model and theory of planned behavior (C-TAM-TPB) model was also employed to examine the acceptance of this mobile service among seniors. As the sensing technology, we proposed a radio frequency identification (RFID) sensing technology based on the Internet of Things (IoT) to construct a platform for a mobile shopping service. In addition, a merchandise search, shopping guide, advertising, and mobile payment were also equipped as elements within the system. The acceptance of a mobile service by seniors may depend on whether its interface is easy to learn and whether its functions are easily understandable. These are key factors affecting seniors' attitude toward the mobile service. The results of our study indicate that seniors' perceptions of the mobile service (perceived usefulness and ease of use of RFID sensing) positively affect their attitude toward using the mobile service, which will further affect their purchase intention. The results also offer an insight into the needs of seniors and highlight some social issues about elderly care.

\section{Introduction}

In 1993, Taiwan became an aging society as defined by the World Health Organization, with an elderly population (65 or older) exceeding 7\% of the country's total population. According to the National Development Council (2018), the elderly population of Taiwan is expected to constitute $20 \%$ of the total population in 2026 , by which time, Taiwan will be recognized as a hyper-aged society, as are Japan, South Korea, Singapore, and some countries in Europe. Moreover, this population ratio will further increase from $14.5 \%$ in 2018 to $41.2 \%$ in 2065 . $^{(1)}$

Web app use via mobile devices has been rising among seniors and will become a common activity for them in the near future. A 2016 survey conducted by the Institute for Information Industry (III) shows that TV shopping ranks third on the list of shopping behaviors of seniors, the top two being traditional buying methods and buying by family members. About $10 \%$ of seniors regularly buy merchandise from TV channels, and of the merchandise they buy, the most commonly bought are daily necessities (43.5\%). A 2017 survey of seniors' buying behavior

*Corresponding author: e-mail: ray@isu.edu.tw https://doi.org/10.18494/SAM.2021.3194 
conducted by III shows that of the people aged 55 years or older in Taiwan, $60.2 \%$ own a mobile phone, $25.1 \%$ a computer, and $7.2 \%$ a tablet PC; those without any digital device account for $38.3 \%{ }^{(2)}$

\subsection{Mobile shopping services vehicle in Japan}

There are more seniors but fewer convenience stores in the countryside in Japan, where seniors unable to do their own shopping are sometimes called "shopping refugees". Some supermarkets or food suppliers supply foods such as fruit, vegetables, and meat to seniors via a "moving supermarket" (truck). Such services have not only helped attract customers but are also in the public interest. A door-to-door delivery service is also available to provide seniors with vegetables, sashimi, and side dishes. For seniors living alone or small households of only two people, this service is extremely convenient.

\subsection{Amazon's treasure truck}

Amazon.com launched an innovative mobile sales model called the Treasure Truck in 2016. By using the free Amazon app and texting "TRUCK" to "24193" to sign up for text alerts, shoppers can receive alerts when Amazon's Treasure Truck is in their area with deals. Inside the Treasure Truck, there are specially selected items on sale for discounted prices. After signing up to Amazon.com for text notifications, customers are alerted of the deals of the day, which range from books to locally produced steak. In this way, Amazon.com is attempting to create an interesting and unprecedented retail model. To buy a special offer from the Treasure Truck, consumers can find "Treasure Truck" in the Amazon app and check out the offers. After customers place their order, they select a convenient pickup location and timeslot to get their item. Customers can also place orders directly from the truck. Since its initial launch, the Treasure Truck has acquired millions of text message subscribers.

\subsection{Traditional mobile sales in Taiwan: vegetable vending trucks}

In the past agricultural society of Taiwan, people shopped for items they needed from morning markets, evening markets, traditional grocery stores, and vegetable vending trucks. Vegetable vending trucks would move from one village to another and usually stop at the same locations at approximately the same times. People living far from a market would rely on vegetable vending trucks that arrived at specific times of the day. These vending trucks allowed people, especially seniors and women with children, to buy necessary items without traveling a long way.

\subsection{Combined technology acceptance model and theory of planned behavior (C-TAM-TPB) model}

Both Mathieson ${ }^{(3)}$ and Taylor and Todd ${ }^{(4)}$ have conducted an empirical analysis and comparison of the technology acceptance model (TAM) and theory of planned behavior 
(TPB). Their empirical findings indicate that both TAM and TPB demonstrate good power in explaining the adoption of information technology.

Taylor and Todd ${ }^{(5)}$ mentioned that although TAM's power in predicting the intention to use and actual usage of a new technology has been supported by a large body of literature, TAM does not consider two important factors, namely, social and control factors. These two factors have been empirically confirmed to have an effect on the adoption of a new technology. In fact, these are the key factors in TPB. Therefore, Taylor and Todd ${ }^{(5)}$ combined TAM and TPB by including subjective norms and perceived behavioral control into TAM. In addition, modified TAM and TPB have been adopted in research on how to establish commitment to environmentally sustainable behavior via other dimensions based on a sustainable modified TAM. ${ }^{(6)}$ The research explored the effects of the perceived value, usefulness, and ease of use of the radio frequency identification (RFID) sensing, subjective norms, and perceived behavioral control on green loyalty in relation to a public bike system.

\subsection{Motivation and objectives}

The 21st century has a social structure characterized by an increasingly growing elderly population. New merchandise and services are being developed to meet the needs of this population. According to Industrial Technology Research Institute, the business opportunities in the seniors' market in Taiwan will reach NT\$3.5937 trillion dollars by $2025 .{ }^{(2)}$ Obviously, the massive business opportunities driven by the so-called silver economy cannot be ignored. In addition to shopping, seniors will encounter more and more issues related to elderly life and care as they age. They may need care and assistance in many aspects of daily life, so the underlying business opportunities are considerable.

With the growth of the elderly population and the development of information technologies, it has become necessary for industries to develop a business model that meets the needs and preferences of seniors. Among this ever-expanding elderly population, some people, despite having good purchase power, are constrained by certain factors when they need to go shopping. For example, the nearest supermarket may be more than $500 \mathrm{~m}$ away and they do not have a car, cannot drive, or have mobility difficulties. The shopping needs of these people are often overlooked. The difficulties and needs of so-called shopping refugees are where business opportunities lie. In their daily lives, there are many occasions in which such people need care and assistance. How information technologies can be applied to satisfy their needs is an issue worth more attention and investigation.

In this study, we use the combined TAM and TPB (C-TAM-TPB) model proposed by Taylor and $\mathrm{Todd}^{(5)}$ as the foundation to develop a research structure, and then apply structural equation modeling (SEM) to explore the causal relationship between various factors associated with mobile shopping services among seniors. The objectives of this study are as follows:

(1) Develop a mobile service website, namely, Senior GO, to provide seniors with shopping.

(2) Utilize an RFID sensing technology to construct a platform for mobile shopping services.

(3) Integrate TPB and TAM models to evaluate the mobile service model for seniors.

(4) Provide suggestions for providers of mobile shopping services for seniors based on the analysis results. 


\subsection{Definition of seniors}

Past definitions of seniors have been guided by WHO, which defined adults aged 65 years or above as seniors or "elderly people". In III's 2017 report on the shopping behavior of seniors, seniors referred to adults aged 55 or older. In this research, we define seniors as people aged 55 or older and use this definition in subsequent analyses.

\section{Materials and Methods}

\subsection{Development of a mobile service model}

We propose a mobile service model called "Senior GO". This model integrates RFID sensing technology, website services (via an app), and a mobile shopping truck. A Senior GO mobile shopping truck will be loaded with merchandise needed by seniors, then transported to locations where seniors usually gather to provide a variety of services to them. The Senior GO system is composed of five parts: identification, merchandise search, shopping guide, advertising, and mobile payment. RFID tags based on an Internet of Things (IoT) shopping guide system are attached to the merchandise. The most critical issue is how to identify the merchandise and how to get merchandise information. Thus, we developed an RFID mobile service model based on IoT and then analyzed the acceptance model of mobile shopping services.

Furthermore, we designed a means of scanning a QR code so that people can add the official account of Senior GO into their friends lists in social networks. Through these social networks, they can get the latest information on when and where the mobile shopping truck will appear and what will be available. The mobile shopping model is shown in Fig. 1.

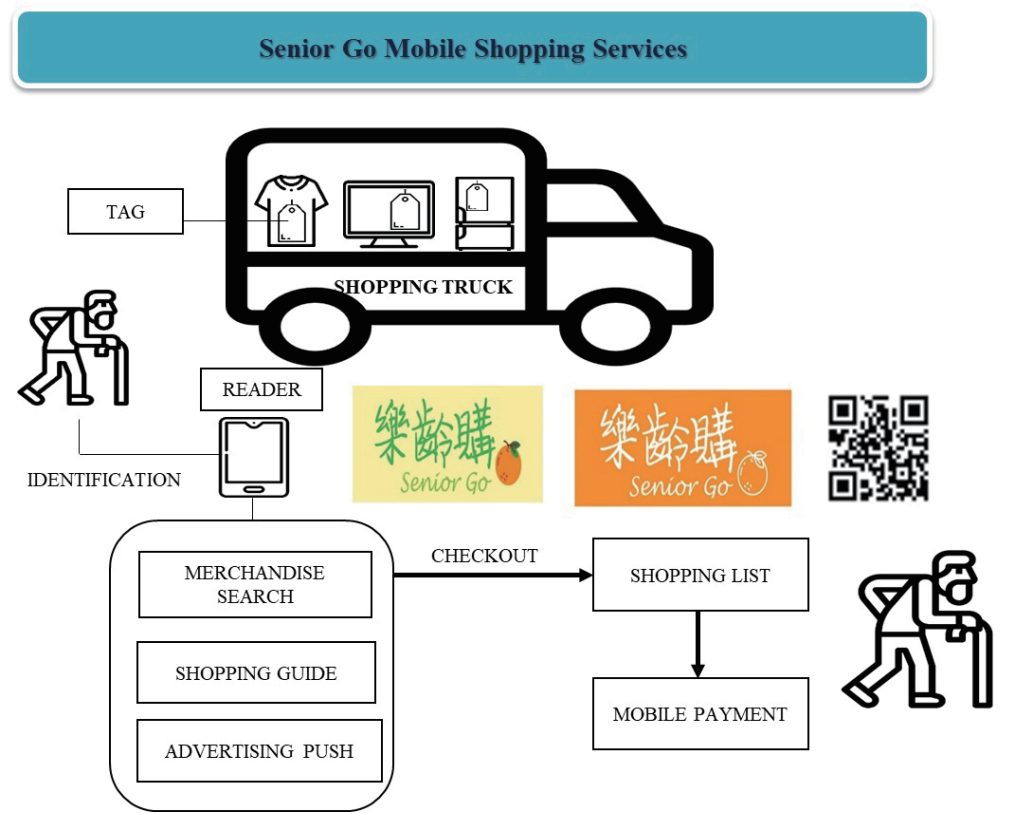

Fig. 1. (Color online) Senior GO mobile shopping system. 
For the design of the mobile shopping truck, we use orange as the corporate color and corporate identity. The design idea came from "Generation Orange", which refers to a relatively young subgroup of the elderly population aged 55-65 years. If we liken the stages of human life to the four seasons of a year, these people are like autumn's maple leaves, which look warm and mature. The intention of the model is to cater to their needs by selling them merchandise, doing their shopping, and providing additional services, such as unlocking and cleaning, to develop "orange" business opportunities.

The mobile shopping truck will be loaded with a wide variety of merchandise selected by Senior GO, including local goods, local food, and daily items. It will be transported to street corners, active ageing centers, community colleges, temples, churches, and other places that seniors usually gather. It will stay a few hours at each stopping point and play old-fashioned music to attract people. This car will carry a certain amount of excellent-value merchandise to be sold at a special price, with the items on special offer changed every time. There is also a limit on the number of such items that can be purchased.

Seniors can get the latest information on the Senior GO mobile shopping truck through social networks. When the mobile shopping truck arrives in their vicinity, they will receive notifications about the merchandise of the day from Senior GO's official account. This will allow them to instantly check what is available, how much it costs, and where exactly the mobile shopping truck is. If they want to buy any item, they can directly order it from the official website and select the pickup location and time that are best for them. When the truck arrives at the selected pickup point, they just need to show the order and buyer information. After completing the payment on site with cash or via an online payment mechanism, they can retrieve their order from the mobile shopping truck. Senior GO users can also buy merchandise directly from the mobile shopping truck.

In addition, there will be staff introducing the merchandise on sale and assisting users with placing orders. The staff will also offer care and assistance to seniors. It is hoped that the merchandise and services available on the mobile shopping truck will arouse anticipation in seniors, thus not only satisfying needs but also adding fun to people's lives.

\subsection{Research framework and hypotheses}

In this study, we employ the C-TAM-TPB model proposed by Taylor and $\operatorname{Todd}^{(5)}$ as the foundation of our research framework and use a mobile service model to investigate seniors' acceptance of mobile shopping services. On the basis of related literature and our research motivation and objectives, we develop our research framework as illustrated in Fig. 2.

On the basis of the dimensions of the C-TAM-TPB model, we propose seven hypotheses to examine seniors' acceptance of mobile shopping services.

H1: Perceived usefulness of RFID sensing is positively and significantly related to attitude toward use.

H2: Perceived ease of use of RFID sensing is positively and significantly related to attitude toward use.

H3: Attitude toward use is positively and significantly related to behavioral intention. 


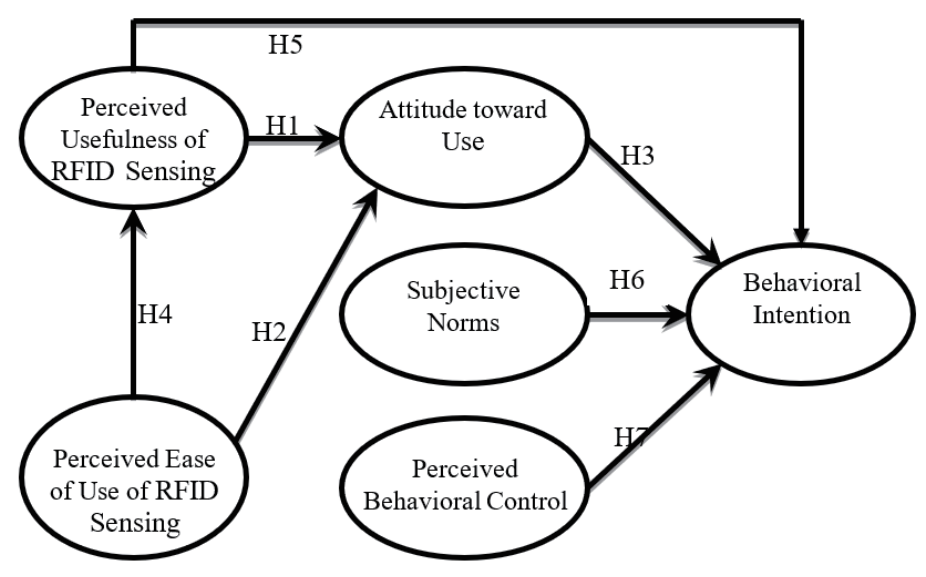

Fig. 2. C-TAM-TPB model.

H4: Perceived ease of use of RFID sensing is positively and significantly related to perceived usefulness of RFID sensing.

H5: Perceived usefulness of RFID sensing is positively and significantly related to behavioral intention.

H6: Subjective norms are positively and significantly related to behavioral intention.

H7: Perceived behavioral control is positively and significantly related to behavioral intention.

\subsection{Operational definitions of research variables}

In accordance with Davis, ${ }^{(7)}$ we define the perceived usefulness of RFID sensing as the degree to which consumers believe that using RFID sensing for a particular merchandise or service leads to a better life, and we define the perceived ease of use of RFID sensing as the degree to which consumers believe that using a new information system with RFID sensing is easy and free of effort. This definition of attitude toward use is based on Ajzen and Fishbein's ${ }^{(8)}$ research. It is defined as consumers' positive attitude toward using a new information service or merchandise.

The definition of subjective norms is adapted from Fishbein and Ajzen, ${ }^{(8,9)}$ who defined them as the perceived social pressure that influences one to perform a particular behavior. For perceived behavioral control, we propose a definition in accordance with Ajzen ${ }^{(10,11)}$ as one's perceived control over the opportunities and resources required for performing a particular behavior. This definition of behavioral intention is based on Fishbein and Ajzen's ${ }^{(9)}$ definition as the tendency that one is willing to buy a particular product.

\subsection{Questionnaire design}

We used a mobile service model that integrates IT applications to investigate seniors' acceptance of mobile shopping services. The subjects of our questionnaire were seniors aged 55 or older in Taiwan having the habit of using smart electronic devices. It was checked that they 
understood the definition of our mobile service model before answering the questionnaire.

The questions in our questionnaire were adapted from those of Taylor and Todd ${ }^{(4,5)}$ and designed to be rated on a five-point Likert scale of "strongly agree" (5 points), "agree" (4 points), "neutral" ( 3 points), "disagree" ( 2 points), and "strongly disagree" (1 point). For each question, participants had to evaluate which answer best expresses their opinion. After the survey, the total score for each participant was calculated for subsequent analysis.

\subsection{Data analysis method}

After all the responses were collected, we examined the responses to exclude those containing incomplete or unreliable data, then entered the valid responses into a database. We used R language to analyze the collected data. The analysis methods we used were sample composition analysis, multiple choice and cross analysis, descriptive statistics analysis, reliability and validity tests, and SEM. The R language used for SEM is shown in Appendix 1.

\section{Analysis Results}

\subsection{Sample profile analysis}

The questionnaire was administered from November 31 to December 30, 2018 to citizens aged 55 or older. A total of 380 copies of the questionnaire were distributed. Before the survey, we first contacted each community college in Taichung City by phone and asked for their assistance with our survey. Later, we visited each college to administer the survey and test run the Senior GO website. After a thorough review, we found that four responses were provided by participants not in our specified age group. The remaining 376 valid responses resulted in a valid response rate of $98.9 \%$.

\subsection{Analysis of demographic variables}

Here, we analyze the demographic variables of the sample, including gender, age, education level, average monthly expenditure on household items, and average frequency of buying household items per month. Our sample mainly consists of females, accounting for $60.9 \%(n=$ 229 persons) of respondents, with males making up 39.1\% ( $n=147$ persons).

As shown in Table 1, most respondents are in the age group of 55-60 years old, accounting for $33.5 \%$ of the sample. The second largest age group is $66-70$ years old $(24.7 \%)$, followed by the age group of 61-65 years old (20.2\%).

As shown in Table 2, in terms of education level, the largest group is senior high/vocational school, which is followed by college/university, and junior high school or lower. The smallest group is masters/doctorate. The four groups respectively account for 38.7, 33.3, 21.3, and 6.7\% of the sample. 
Table 1

Analysis by age.

\begin{tabular}{lcc}
\hline Age & $n$ (persons) & Percentage $(\%)$ \\
\hline $55-60$ & 126 & 33.5 \\
$61-65$ & 76 & 20.2 \\
$66-70$ & 93 & 24.7 \\
$71-75$ & 46 & 12.2 \\
76 or older & 35 & 9.3 \\
\hline
\end{tabular}

Table 2

Analysis by education level.

\begin{tabular}{lcc}
\hline Level of education & $n$ (persons) & Percentage (\%) \\
\hline Junior high school or lower & 80 & 21.3 \\
Senior high/vocational & 146 & 38.7 \\
school & 125 & 33.3 \\
College/university & 25 & 6.7 \\
Masters/doctorate &
\end{tabular}

\subsection{Descriptive statistics}

The research data were collected using a questionnaire designed with a five-point Likert scale. On the basis of the participants' responses, we analyzed the descriptive statistics for six research variables: perceived usefulness and ease of use of RFID sensing from TAM, and subjective norms, perceived behavioral control, attitude toward use, and behavioral intention from TPB.

As listed in Table 3, there are a total of seven items in these two dimensions. The means of these items range between 3.68 and 4.03, suggesting that most participants showed a moderate level of agreement with the perceived usefulness and ease of use of RFID sensing of the proposed mobile service model. Moreover, all the items have a standard deviation smaller than 1 , indicating that most participants shared similar views with regard to the questionnaire items.

As shown in Table 4, we measured attitude toward use with four items and subjective norms with two items. The means of these items range between 3.66 and 4.13, indicating that most participants gave a positive or neutral response to the questions in these two dimensions. All the items have a standard deviation below 1 , meaning that there is a high consistency of opinions among the participants.

As shown in Table 5, the perceived behavioral control and behavioral intention dimensions consist of a total of five items. The means of these items range between 3.92 and 4.13, implying that most participants gave a positive or neutral response to the items in these two dimensions. Again, all the standard deviations are smaller than 1, indicating that most participants share similar views on the items in these dimensions.

\subsection{Reliability and validity analyses}

In this study, we measured the reliability of the questionnaire using Cronbach's $\alpha$ coefficient. According to Guilford, ${ }^{(12)}$ a Cronbach's $\alpha$ lower than 0.35 indicates low reliability. An acceptable score is between 0.35 and 0.7 , and a score greater than 0.7 indicates high reliability. According to Table 6, all the dimensions have a Cronbach's $\alpha$ greater than 0.7, meaning that all the dimensions have high reliability and consistency.

Bagozzi and $\mathrm{Yi}^{(13)}$ suggested that $R^{2}$ greater than 0.40 or a factor loading above 0.50 indicates the significance of a variable. As shown in Table 7, all the items have an $R^{2}$ value between 0.70 and 0.82 and a factor loading between 0.84 and 0.94 , indicating the significance of the variables they are meant to measure. 
Table 3

Descriptive statistics for perceived usefulness and ease of use of RFID sensing.

\begin{tabular}{|c|c|c|c|c|}
\hline Dimension & Item No. & Questionnaire item & Mean & S.D. \\
\hline \multirow{4}{*}{$\begin{array}{l}\text { Perceived } \\
\text { usefulness of } \\
\text { RFID sensing } \\
\text { (pu) }\end{array}$} & pul & $\begin{array}{l}\text { A mobile service with RFID sensing would be helpful to my } \\
\text { everyday life. }\end{array}$ & 3.92 & 0.94 \\
\hline & pu2 & $\begin{array}{l}\text { I could get shopping information and assistance by using the } \\
\text { mobile service with RFID sensing technology. }\end{array}$ & 3.86 & 0.87 \\
\hline & pu3 & $\begin{array}{l}\text { A mobile service with RFID sensing technology could add } \\
\text { convenience to my everyday life. }\end{array}$ & 4.03 & 0.88 \\
\hline & pu4 & $\begin{array}{l}\text { A mobile service with RFID sensing technology would help me do } \\
\text { my shopping more efficiently. }\end{array}$ & 3.96 & 0.89 \\
\hline \multirow{3}{*}{$\begin{array}{l}\text { Perceived } \\
\text { ease of use of } \\
\text { RFID sensing } \\
\text { (pe) }\end{array}$} & pel & $\begin{array}{l}\text { Learning how to use the mobile service with RFID sensing } \\
\text { technology would be easy and free of effort. }\end{array}$ & 3.68 & 0.93 \\
\hline & pe2 & $\begin{array}{l}\text { A mobile service with RFID sensing technology would be easy to } \\
\text { use. }\end{array}$ & 3.72 & 0.91 \\
\hline & pe3 & $\begin{array}{l}\text { A mobile service with RFID sensing technology could offer instant } \\
\text { support for my shopping. }\end{array}$ & 3.71 & 0.9 \\
\hline
\end{tabular}

Table 4

Descriptive statistics for attitude toward use and subjective norms.

\begin{tabular}{|c|c|c|c|c|}
\hline Dimension & Item No. & Questionnaire item & Mean & S.D. \\
\hline \multirow{4}{*}{$\begin{array}{l}\text { Attitude } \\
\text { toward use } \\
\text { (atu) }\end{array}$} & atul & I like the software and hardware design of the mobile service. & 3.66 & 0.89 \\
\hline & atu2 & It would be worth using the mobile service with RFID sensing. & 3.91 & 0.82 \\
\hline & atu3 & A mobile service with RFID sensing would be reliable. & 3.81 & 0.86 \\
\hline & atu4 & $\begin{array}{l}\text { I would be willing to use the mobile service with RFID sensing } \\
\text { technology. }\end{array}$ & 3.83 & 0.91 \\
\hline \multirow{2}{*}{$\begin{array}{l}\text { Subjective } \\
\text { norms (sn) }\end{array}$} & sn1 & $\begin{array}{l}\text { The active ageing center and the community would provide } \\
\text { adequate assistance to help me get used to using the mobile service } \\
\text { with RFID sensing technology. }\end{array}$ & 4.04 & 0.84 \\
\hline & $\operatorname{sn} 2$ & $\begin{array}{l}\text { The active ageing center and community would be actively engaged } \\
\text { in promoting the use of the mobile service with RFID sensing } \\
\text { technology. }\end{array}$ & 4.13 & 0.79 \\
\hline
\end{tabular}

Table 5

Descriptive statistics for perceived behavioral control and behavioral intention.

\begin{tabular}{lcccc}
\hline Dimension & Item No. & Questionnaire item & Mean & S.D. \\
\hline $\begin{array}{l}\text { Perceived } \\
\text { behavioral } \\
\text { control (pbc) }\end{array}$ & pbc1 & $\begin{array}{c}\text { The mobile service with RFID sensing technology would offer a } \\
\text { platform suitable for seniors to do their shopping. }\end{array}$ & 4.13 & 0.83 \\
\cline { 2 - 6 } & bi1 & $\begin{array}{c}\text { If the mobile service with RFID sensing technology is available } \\
\text { at fixed times and locations, I will regularly buy things from this } \\
\text { service platform. }\end{array}$ & 4.10 & 0.81 \\
\cline { 2 - 6 } & bi2 & $\begin{array}{c}\text { The mobile service using RFID sensing technology sounds very } \\
\text { useful, and I can't wait to use it. }\end{array}$ & 3.92 & 0.86 \\
\cline { 2 - 6 } $\begin{array}{l}\text { Behavioral } \\
\text { intention (bi) }\end{array}$ & bi3 & $\begin{array}{c}\text { The mobile service using RFID sensing technology sounds very } \\
\text { useful, and I will recommend it to my relatives and friends. }\end{array}$ & 3.93 & 0.84 \\
\hline
\end{tabular}

Table 6

Reliability of each dimension.

\begin{tabular}{|c|c|c|c|}
\hline Dimension & Cronbach's $\alpha$ & Dimension & Cronbach's $\alpha$ \\
\hline Perceived usefulness of RFID sensing & 0.930 & Subjective norms & 0.875 \\
\hline Perceived ease of use of RFID sensing & 0.921 & Perceived behavioral control & 0.848 \\
\hline Attitude toward use & 0.921 & Behavioral intention & 0.925 \\
\hline
\end{tabular}


Table 7

Confirmatory factor analysis.

\begin{tabular}{|c|c|c|c|c|}
\hline Dimension & Factor loading & $R^{2}$ & $\mathrm{CR}$ & AVE \\
\hline \multicolumn{5}{|c|}{ Perceived usefulness of RFID sensing (pu) } \\
\hline pu1 & 0.88 & 0.78 & \multirow{4}{*}{0.93} & \multirow{4}{*}{0.77} \\
\hline pu2 & 0.87 & 0.75 & & \\
\hline pu3 & 0.91 & 0.82 & & \\
\hline pu4 & 0.86 & 0.74 & & \\
\hline \multicolumn{5}{|c|}{ Perceived ease of use of RFID sensing (pe) } \\
\hline pel & 0.88 & 0.78 & \multirow{3}{*}{0.92} & \multirow{3}{*}{0.79} \\
\hline pe2 & 0.94 & 0.87 & & \\
\hline pe3 & 0.86 & 0.73 & & \\
\hline \multicolumn{5}{|c|}{ Attitude toward use (atu) } \\
\hline atu1 & 0.84 & 0.70 & \multirow{4}{*}{0.92} & \multirow{4}{*}{0.75} \\
\hline atu2 & 0.87 & 0.76 & & \\
\hline atu3 & 0.87 & 0.76 & & \\
\hline atu4 & 0.88 & 0.78 & & \\
\hline \multicolumn{5}{|c|}{ Subjective norms (sn) } \\
\hline sn1 & 0.87 & 0.75 & \multirow{2}{*}{0.88} & \multirow{2}{*}{0.78} \\
\hline $\operatorname{sn} 2$ & 0.90 & 0.81 & & \\
\hline \multicolumn{5}{|c|}{ Perceived behavioral control (pbc) } \\
\hline pbc1 & 0.87 & 0.76 & \multirow{2}{*}{0.85} & \multirow{2}{*}{0.74} \\
\hline pbc2 & 0.85 & 0.72 & & \\
\hline \multicolumn{5}{|c|}{ Behavioral intention (bi) } \\
\hline bil & 0.88 & 0.77 & \multirow{3}{*}{0.92} & \multirow{3}{*}{0.78} \\
\hline bi2 & 0.89 & 0.79 & & \\
\hline bi3 & 0.89 & 0.79 & & \\
\hline
\end{tabular}

According to Fornell and Larcker, ${ }^{(14)}$ composite reliability (CR) above 0.60 suggests high $\mathrm{CR}$, and to demonstrate convergent validity, average variance extracted (AVE) should be greater than 0.50 . We conducted a confirmatory factor analysis to evaluate the questionnaire. As shown in Table 7, CR values range between 0.85 and 0.93 and are all greater than 0.60; AVE values range between 0.74 and 0.79 and are all greater than 0.50 . Therefore, the convergent validity of our questionnaire is confirmed.

\subsection{SEM}

We also applied $\mathrm{R}$ language to perform SEM analysis. Three types of goodness-offit measure, namely, absolute fit measures, incremental fit measures, and parsimonious fit measures, were used in the analysis to verify the proposed hypotheses.

Absolute goodness-of-fit measures indicate the degree to which the sample covariance matrix is explained by the model covariance matrix. The commonly used absolute measures are as follows. (1) Goodness-of-fit index (GFI). This is a measure of the relative values of variance and covariance explained by the model. GFI ranges from 0 to 1 , with values closer to 1 indicating a better fit. The suggested level for GFI indicating a good fit is 0.80 or greater. $^{(15)}$ (2) Adjusted goodness-of-fit index (AGFI). This measure adjusts GFI to take account of the degree of freedom. When the number of parameters in the model is large, a large AGFI value is 
obtained. The suggested level for AGFI indicating a good fit is 0.80 or greater. ${ }^{(16)}$ (3) Root mean square error of approximation (RMSEA). This is a "badness of fit" index, which is less affected by sample size than the other indices. Large RMSEA values indicate a low goodness-of-fit between the model and data. It has been recognized as an important fitting measure in recent years, and many studies have indicated that it is more indicative of model fitting than other indices. The suggested level for RMSEA indicating a good fit is 0.10 or lower. ${ }^{(17)}$ All indices were adopted in the analysis. The absolute goodness-of-fit measures for our theoretical model are GFI $=0.88$, AGFI $=0.83$, and RMSEA $=0.09$. These values indicate the good goodness-offit of our model.

We adopted four incremental fit measures. (1) Normed fit index (NFI). This is an alternative to the comparative fit index (CFI). The values of NFI range from 0 to 1 , and a value greater than 0.90 indicates a good fit. ${ }^{(18,19)}$ (2) Non-normed fit index (NNFI). This is an adjusted index of NFI that considers model complexity, with values closer to 1 indicating a better fit. For a good fit, NNFI should be 0.90 or greater. ${ }^{(18,19)}$ (3) Relative fit index (RFI). This index is derived from NFI and ranges from 0 to 1 , with values closer to 1 indicating a better model fit. A value of 0.90 or greater indicates a good fit. ${ }^{(20,21)}$ (4) CFI. Similarly to RMSEA, CFI is less affected by sample size than the other indices. CFI values closer to 1 indicate a better model fit and greater centrality. A CFI value of 0.90 or greater indicates a good fit. ${ }^{(2)}$ The incremental fit measures for our theoretical model are NFI $=0.92, \mathrm{NNFI}=0.92$, RFI $=0.90$, and CFI $=0.94$. All these values are greater than the suggested level of 0.90 , indicating the good fit of our model.

Parsimonious goodness-of-fit measures are evaluated if a model is complicated. Among similar models created for the same sample, those with higher values of parsimonious fit measures are considered better. Parsimonious goodness-of-fit measures include the following. (1) Parsimonious goodness-of-fit index (PGFI). This considers the number of parameters to be estimated in the model, so it can reflect the parsimony of a SEM model. PGFI values closer to 1 indicate higher parsimony, and a value of 0.50 or greater is considered a good fitting. ${ }^{(23)}$ (2) Chi-square/degree of freedom ratio $\left(\chi^{2} / \mathrm{df}\right)$, for which a smaller ratio indicates a better goodness-of-fit. According to Schumacker and Lomax, ${ }^{(24)}$ a ratio of 5 or smaller indicates an acceptable goodness-of-fit. These two indices were adopted in our analysis. We obtained PGFI $=0.64$ and $\chi^{2} / \mathrm{df}=4.27$, demonstrating that our model has a good goodness-of-fit. The results for each fit measure are summarized in Table 8 .

Table 8

Results of goodness-of-fit measures for the model.

\begin{tabular}{lccc}
\hline & GFI & Suggested value & Result \\
\hline \multirow{3}{*}{ Absolute goodness-of-fit measures } & GFI & $\geq 0.8$ & 0.88 \\
\cline { 2 - 4 } & AGFI & $\geq 0.8$ & 0.83 \\
\cline { 2 - 4 } Incremental goodness-of-fit measures & RMSEA & $\leq 0.1$ & 0.09 \\
\cline { 2 - 4 } & NFI & $\geq 0.9$ & 0.92 \\
\cline { 2 - 4 } & NNFI & $\geq 0.9$ & 0.92 \\
\cline { 2 - 4 } Parsimonious goodness-of-fit measures & RFI & $\geq 0.9$ & 0.90 \\
\cline { 2 - 3 } & CFI & $\geq 0.9$ & 0.94 \\
\cline { 2 - 3 } & PGFI & $\leq 5$ & 4.27 \\
\hline
\end{tabular}


As shown in Fig. 3 and Table 9, the path coefficient for the relationship between perceived usefulness of RFID sensing and attitude toward use (H1) is 0.59 , with $p$-value $<0.001$, suggesting that the perceived usefulness of RFID sensing has a significantly positive effect on attitude toward use. The relationship between perceived ease of use of RFID sensing and attitude toward use (H2) has a path coefficient of 0.41 and $p$-value $<0.001$, indicating that perceived ease of use of RFID sensing is positively and significantly related to attitude toward use.

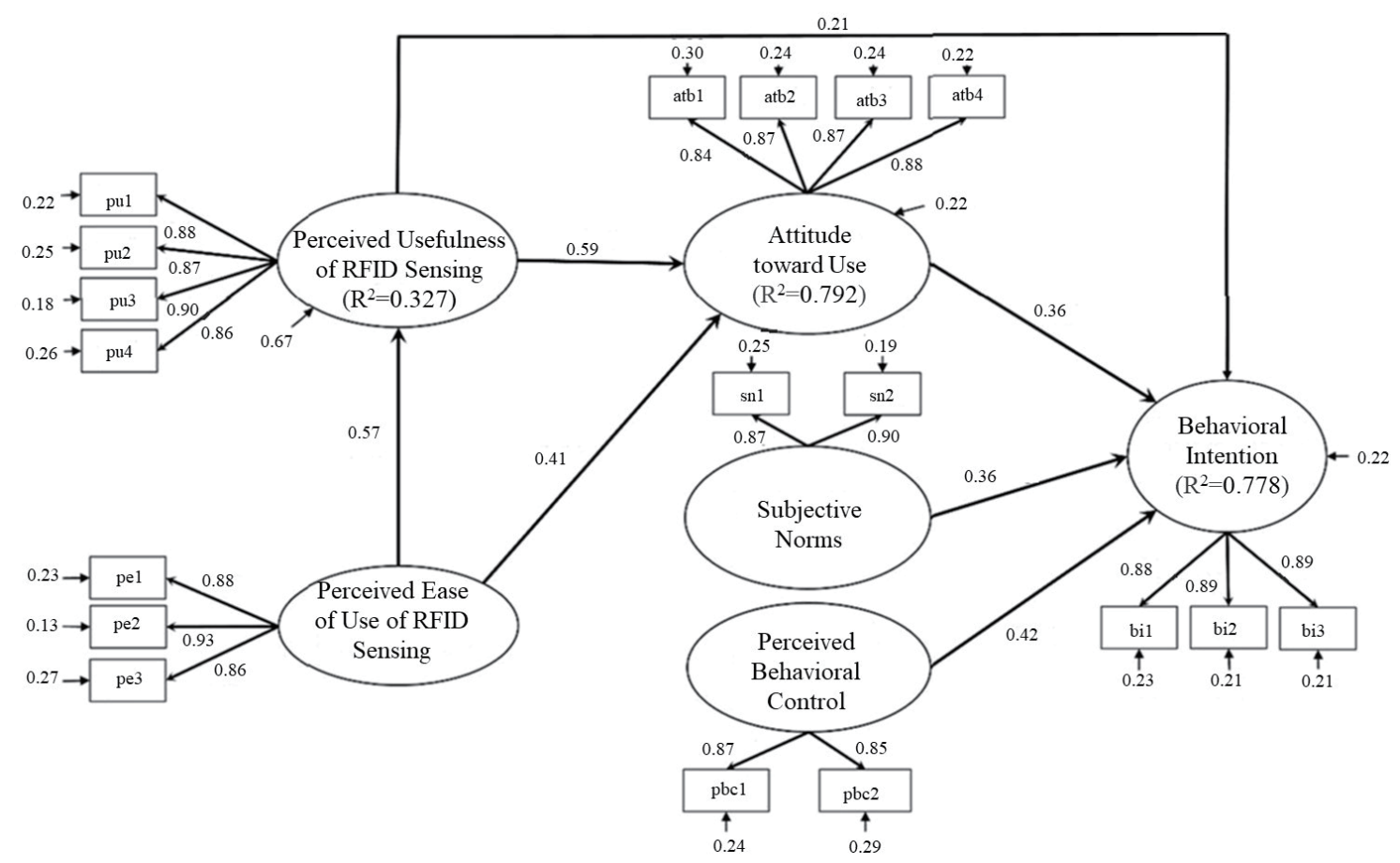

Fig. 3. SEM path analysis diagram.

Table 9

Hypothesis testing results.

\begin{tabular}{|c|c|c|c|}
\hline Hypothesis & Relationship & $\begin{array}{l}\text { Path correlation } \\
\text { coefficient }\end{array}$ & Result \\
\hline $\mathrm{H} 1$ & $\begin{array}{l}\text { Perceived usefulness of RFID sensing is positively and } \\
\text { significantly related to attitude toward use. }\end{array}$ & $0.59 * * *$ & Supported \\
\hline $\mathrm{H} 2$ & $\begin{array}{l}\text { Perceived ease of use of RFID sensing is positively and } \\
\text { significantly related to attitude toward use. }\end{array}$ & $0.41 * * *$ & Supported \\
\hline $\mathrm{H} 3$ & $\begin{array}{l}\text { Attitude toward use is positively and significantly related to } \\
\text { behavioral intention. }\end{array}$ & $0.36 * * *$ & Supported \\
\hline $\mathrm{H} 4$ & $\begin{array}{l}\text { Perceived ease of use of RFID sensing is positively and } \\
\text { significantly related to perceived usefulness. }\end{array}$ & $0.57 * * *$ & Supported \\
\hline H5 & $\begin{array}{l}\text { Perceived usefulness of RFID sensing is positively and } \\
\text { significantly related to behavioral intention. }\end{array}$ & $0.21 * * *$ & Supported \\
\hline H6 & $\begin{array}{c}\text { Subjective norms are positively and significantly related to } \\
\text { behavioral intention. }\end{array}$ & $0.36 * * *$ & Supported \\
\hline $\mathrm{H} 7$ & $\begin{array}{c}\text { Perceived behavioral control is positively and significantly } \\
\text { related to behavioral intention. }\end{array}$ & $0.42 * * *$ & Supported \\
\hline
\end{tabular}


For the relationship between attitude toward use and behavioral intention (H3), the analysis yields a path coefficient of 0.36 and $p$-value $<0.001$. This suggests that attitude toward use has a significantly positive effect on behavioral intention. The relationship between perceived ease of use and perceived usefulness of RFID sensing (H4) has a path coefficient of 0.57 and $p$-value $<0.001$, indicating that perceived ease of use and perceived usefulness of RFID sensing are positively and significantly related.

The path coefficient for the relationship between perceived usefulness of RFID sensing and behavioral intention (H5) is 0.21 , with $p$-value $<0.001$, suggesting that the perceived usefulness of RFID sensing has a significantly positive effect on behavioral intention. For the relationship between subjective norms and behavioral intention (H6), we obtained a path coefficient of 0.36 and $p$-value $<0.001$, indicating that subjective norms have a significantly positive effect on behavioral intention. The relationship between perceived behavioral control and behavioral intention (H7) has a path coefficient of 0.42 and $p$-value $<0.001$, suggesting that there is a significant and positive relationship between perceived behavioral control and behavioral intention. The above results are obtained using the parameters estimated in the SEM. As shown in Table 9, all the proposed hypotheses are supported.

\section{Discussion}

To improve the quality of life (e.g., through meeting shopping needs in this study) and solve the problems that seniors have in moving freely, we designed the Senior GO mobile shopping service for seniors to shop conveniently. The system included a web/mobile application providing a merchandise search, shopping guide, advertising, and promotion information for consumers, an RFID sensing system, and a payment system. Thus, the implementation is designed in consideration of the usefulness and ease of usage for seniors wishing to shop.

The C-TAM-TPB model proposed by Taylor and $\operatorname{Todd}^{(5)}$ indicates that consumers' attitude toward using a new information technology such as RFID sensing is primarily affected by perceived usefulness and ease of use, and such an attitude has an effect on consumers' actual usage of the technology. When consumers have a positive attitude toward a new technology, they are more likely to have a strong intention to use the technology. Therefore, seniors' acceptance of a mobile service with RFID sensing may depend on whether its website interface is easy to learn and whether its functions are easily understandable. These are key factors affecting seniors' attitude toward the mobile service. Our results support the findings of Ref. 25 and indicate that seniors' perception of the mobile service (perceived usefulness and ease of use of RFID sensing) positively affect their attitude toward using the mobile service, which will further affect their purchase intentions. The C-TAM-TPB model indicates that consumers' buying behavior does not solely depend on their attitude toward merchandise. It is also affected by social factors, subjective factors, and an individual's behavioral control beliefs. In other words, behavioral intention is jointly determined by three factors: attitude toward using, subjective norms, and perceived behavioral control.

In this study, we found that the attitude of seniors toward using a mobile service affects the purchase intention. This finding echoes those of previous studies. ${ }^{(26-29)}$ The website design, 
merchandise sales method, and extra services of the mobile shopping truck all have an impact on their actual usage of the mobile service. With regard to subjective norms, we found that when using the mobile service with RFID sensing technology, seniors have a stronger purchase intention if the mobile service is promoted in the active ageing center or in the community. In summary, seniors' purchase intention is positively and significantly affected by their attitude toward using the mobile service, subjective norms, and perceived behavioral control with the services of RFID sensing.

According to our survey results, groceries are the type of merchandise most seniors hope to be available in the proposed service model, while shopping services are the most keenly anticipated type of service. As to online shopping habits, the LINE app is most widely used among them and Facebook ranks second. In terms of payment methods, cash payment is most popular, followed by credit card.

Overall, most seniors participating in our survey provided a response indicating agreement with each item measuring their acceptance of the mobile service. These items include the convenience of shopping, the ease of use of the interface, the overall evaluation of the mobile service with RFID sensing, the desire for the system to be promoted in active ageing centers and communities, the suitability of the service as a platform for seniors to do their shopping, and the intention to use the service.

\section{Conclusion}

We implemented a mobile shopping service called Senior GO to increase the convenience of shopping for seniors. All the merchandise in the Senior GO mobile shopping truck are equipped with an RFID sensing chip for two purposes: for users to get product information and for sellers to manage the goods. Furthermore, the model also included a web/mobile application providing a merchandise search, shopping guide, advertising, and promotion information for consumers.

To demonstrate that this Senior GO service is attractive to seniors, we evaluated this system by a series of statistical tests. Through hypothesis testing with $\mathrm{R}$ language, multiple response analysis, cross analysis, and interviews with seniors, we confirmed the need for this mobile service among seniors. Hence, we conclude that our findings may be helpful for the senior services industry in addressing the shopping needs of this population. These findings can also be a reference for future researchers and practitioners in this field of shopping using RFID sensing services.

Although we tried to implement and evaluate the proposed business model in a rigorous way, this research still showed some limitations. First, since new technologies are rapidly emerging, this model could be expanded and integrated with more new technologies to improve its functionality. For example, artificial IoT (AIoT) techniques can be used to recognize customers and analyze their buying characteristics and behaviors. Second, theft is one of the critical concerns for stores and also the mobile shopping car. Thus, an anti-theft mechanism or system could be integrated into the shopping services management system to prevent goods from being stolen. 


\section{References}

1 National Development Council, Taiwan: https://www.ndc.gov.tw/en/cp.aspx?n=2E5DCB04C64512CC (accessed November 2018).

2 Institute for Information Industry, Taiwan: https://www.iii.org.tw/Press/NewsDtl.aspx?nsp sqno=1917\&fm $\underline{\text { sqno }}=14$ (accessed November 2018).

3 K. Mathieson: Info. Syst. Res. 2 (1991) 173. https://doi.org/10.1287/isre.2.3.173

4 S. Taylor and P. A. Todd: Info. Syst. Res. 6 (1995a) 144. https://doi.org/10.1287/isre.6.2.144

5 S. Taylor and P. A. Todd: MIS Q. 19 (1995b) 561. https://doi.org/10.2307/249633

6 S. Y. Chen: Transport. Res. A 88 (2016) 58. https://doi.org/10.1016/j.tra.2016.03.008

7 F. D. Davis: MIS Q. 13 (1989) 319. https://doi.org/10.2307/249008

8 I. Ajzen and M. Fishbein: Understanding Attitudes and Predicting Social Behavior (Englewood Cliffs, Prentice-Hall, NJ, 1980).

9 M. Fishbein and I. Ajzen: Belief, Attitude, Intention and Behavior: An Introduction to Theory and Research, Reading (Addison-Wesley, MA, 1975).

10 I. Ajzen: From Intentions to Actions: A Theory of Planned Behavior, SSSP Springer Series in Social Psychology Book Series (SSSOC, 1985) p. 11.

11 I. Ajzen: Organ. Behav. 50 (1991) 179. https://doi.org/10.1016/0749-5978(91)90020-T

12 J. P. Guilford: Fundamental Statistics in Psychology and Education (McGraw Hill, New York, 1965).

13 R. P. Bagozzi and Y. Yi.: J. Acad. Mark. Sci. 16 (1988) 74. https://doi.org/10.1007/BF02723327

14 C. Fornell and D. F. Larcker: J. Mark. Res. 18 (1981) 39. https://doi.org/10.2307/3151312

15 W. J. Doll, W. Xia, and G. Torkzadeh: MIS Q. 18 (1994) 453. https://doi.org/10.2307/249524

16 R. C. MacCallum and S. Hong: Multi. Behav. Res. 32 (1997) 193. https://doi.org/10.1207/s15327906mbr3202_5

17 M. W. Browne and R. Cudeck: Alternative Ways of Assessing Model: Testing Structural Equation Models, Fit. K. A. Bollen and J. S. Long, Eds. (Newbury Park, CA, 1993) p. 136.

18 H. C. Chiu: Structural Equation Model: Theory, Technology, and Applications of LISREL (Double Leaf Book Gallery, Taipei, 2011).

19 P. M. Bentler and D. G. Bonett: Psychol. Bull. 88 (1980) 588. https://doi.org/10.1037/0033-2909.88.3.588

20 F. M. Huang: Structural Equation Model Theory and Application (Wunan Culture Enterprise, Taipei, 2007).

21 K. A. Bollen: Structural Equations with Latent Variables, Applied Probability and Statistics Section (Wiley series in Probability and Mathematical Statistics, 1989).

22 M. N. Li: Introduction to the Structural Equation Model Software Amos and its Application in Test Preparation (Psychology, Taipei, 2006).

23 S. A. Mulaik, L. R. James, J. V. Altine, N. Bennett, S. Lind, and C. D. Stilwell: Psychol. Bull. 105 (1989) 430. https://doi.org/10.1037/0033-2909.105.3.430

24 R. E. Schumacker and R. G. Lomax: A Beginner's Guide to Structural Equation Modeling (Lawrence Erlbaum Associates, NJ, 2004).

25 R. Steele, A. Lo, C. Secombe, and Y. K. Wong: Int. J. Medi Inform. 78 (2009) 788. https://doi.org/10.1016/ j.ijmedinf.2009.08.001

26 R. Lyer and J. K. Eastman: J. Mark. Theor. Pract. 14 (2006) 57. https://doi.org/10.2753/MTP1069-6679140104

27 J. L. H. Birkland: Gerontechnology: Understanding Older Adult Information and Communication Technology Use, (emerald Publishing, UK, 2019) 1st ed., Chap. 7. https://doi.org/10.1108/9781787432918

28 M. Mcmurtrey, S. M. Zeltmann, J. P. Downey, and R. Mcgaughey: J. Comput. Info. Syst. 51 (2011) 22.

29 M. R. Lee, A. N. Chen, R. Mcgaughey, and S. M. Zeltmann: Int. J. Hum-Comput. Int. 34 (2017) 1. https://doi. org/10.1080/10447318.2017.1335445 


\section{Appendix 1. R language for SEM}

library(lavaan)

sem_data $=$ read.csv("C: $\|$ Users $\left.\backslash \backslash J e s s i e ~ Y u\|\backslash D e s k t o p\| l o f f i c i a l \_m u l t i d a t a 4 . c s v "\right)$

sem_model $=$ '

\# measurement model \#

$\mathrm{PU}=\sim \mathrm{pu} 1+\mathrm{pu} 2+\mathrm{pu} 3+\mathrm{pu} 4$

$\mathrm{PE}=\sim$ pe $1+$ pe $2+$ pe 3

$\mathrm{ATB}=\sim \mathrm{atb} 1+\mathrm{atb} 2+\mathrm{atb} 3+\mathrm{atb} 4$

$\mathrm{SN}=\sim \mathrm{sn} 1+\mathrm{sn} 2$

$\mathrm{PBC}=\sim \mathrm{pbc} 1+\mathrm{pbc} 2$

$\mathrm{BI}=\sim$ bi $1+$ bi $2+$ bi 3

$\mathrm{ATB} \sim \mathrm{PU}+\mathrm{PE}$

$\mathrm{BI} \sim \mathrm{ATB}+\mathrm{SN}+\mathrm{PBC}+\mathrm{PU}$

$\mathrm{PU} \sim \mathrm{PE}$

\#SEM Report

sem.fit $=$ sem $($ sem_model, data $=$ sem_data $)$

summary (sem.fit, fit.measures $=$ TRUE, standardized $=$ TRUE, rsquare $=$ TRUE)

standardizedSolution(sem.fit)

sfit $=$ standardizedSolution(sem.fit) 